\title{
Summertime episodic chlorophyll $a$ blooms near the east coast of the Korean Peninsula
}

\author{
Young-Tae Son, Jae-Hyoung Park, and SungHyun Nam \\ School of the Earth and Environmental Sciences/Research Institute of Oceanography, Seoul National University, \\ Seoul 08826, Republic of Korea \\ Correspondence: SungHyun Nam (namsh@snu.ac.kr)
}

Received: 11 April 2018 - Discussion started: 23 April 2018

Revised: 6 July 2018 - Accepted: 9 August 2018 - Published: 30 August 2018

\begin{abstract}
We present intensive observational data of surface chlorophyll $a$ bloom episodes occurring over several days in the summers of 2011, 2012 and 2013, accompanying the equatorward advection of low sea surface salinity (SSS) water near the east coast of the Korean Peninsula. Time-series analysis of meteorological and oceanographic (physical and biochemical) parameter data, such as chlorophyll fluorescence (CF) from surface mooring, ocean color (chlorophyll $a$ and total suspended sediment), sea surface height (satellite-derived) and serial hydrographic data (from in situ measurements), was used to investigate the relationship between surface bloom events and changes in seawater characteristics and currents. In the summers of the 3 years, a total of 10 bloom events (E01-E10) were identified during which the surface CF was significantly $\left(>2 \mu \mathrm{g} \mathrm{L}^{-1}\right)$ enhanced over a relatively long ( $>1$ day) period. The bloom events in the summers of 2011 and 2012 were accompanied by low or decreasing SSS for several days to a week after heavy rainfall at upstream stations and equatorward currents. Unlike the typical 8 of the 10 events $(80 \%)$, E07 was potentially derived from the onshore advection of high CF offshore water of southern origin into the coastal zone near the mooring, whereas E10 possibly prevailed by offshore advection of high CF plume water trapped by the coastal area. Contrasting with many coastal systems, these findings indicate that eventscale productivity near the east coast of the Korean Peninsula in summer is not controlled by local blooms triggered by either nutrients or light availability, but by the equatorward and cross-shore advection of high CF plume water.
\end{abstract}

\section{Introduction}

Biological blooms, associated with, among other phenomena, the horizontal advection of chlorophyll-rich water (often having low salinity and high nutrients linked to heavy rain, e.g., nutrient loading), have been frequently observed in many coastal systems (e.g., Yin et al., 2004; Crespo et al., 2007; Dai et al., 2008; Halverson and Pawlowicz, 2013; Reifel et al., 2013). Blooms stimulated by plume-delivered nutrients and enhanced stratification were observed near and offshore of Hong Kong (Dai et al., 2008; Yin et al., 2004). During bloom events, a severalfold increase in chlorophyll $a$ (Chl $a$ ) and significant shift in phytoplankton community structure were observed (Dai et al., 2008). The effects of effluent discharge plumes on coastal phytoplankton communities were examined from the City of Los Angeles Hyperion Water Reclamation Plant, demonstrating that localized blooms occurred a few days after the plume water discharge (Reifel et al., 2013). The Fraser River plume affects Chl $a$ distribution in the Strait of Georgia, British Columbia, Canada, revealing large $\mathrm{Chl} a$ differences among the local plumes, despite insensitivity in the long-term average (Halverson and Pawlowicz, 2013).

There are several small river plumes potentially affecting Chl $a$ distribution near and offshore of the east coast of the Korean Peninsula; yet, the effects remain poorly understood. High summer (from June to September, JJAS) precipitation often accompanying heavy rainfall around the Korean Peninsula accounts for $>50 \%$ of the annual precipitation in the region. During summer, most rivers in the region become flooded and discharge large volumes of freshwater into the adjacent marginal seas, including the East Sea (Sea of Japan), Yellow Sea and East China Sea (Bae et al., 2008; Kong et al., 
2013). Chl $a$ distribution in the southwestern East Sea off the east coast of the Korean Peninsula has been found to be associated with physical processes at mesoscale or larger scales, including spring and fall blooms that have been detected using satellite ocean color data, data from short-duration ship surveys (Hyun et al., 2008; Kang et al., 2004) and time-series data collected continuously from moored buoys (Hong et al., 2013; Son et al., 2014). Despite wide-range images available from geostationary and polar-orbit satellite ocean color remote sensing (Yoo and Kim, 2004; Son et al., 2014; Hyun et al., 2008; Kim et al., 2011), phytoplankton blooms observed over several days to weeks near the coast, particularly during the well-stratified summer season, have rarely been examined. Thus, we aimed to address the episodic bloom events in summer and investigated the effects of river plumes on Chl $a$ distribution near and away from the east coast of the Korean Peninsula.

\section{Data and methods}

Time-series data of meteorological, physical and biochemical parameters have been measured using a surface mooring named ESROB (East Sea Real-time monitoring Ocean Buoy), deployed at a water depth of $130 \mathrm{~m}$, about $8 \mathrm{~km}$ off the mid-east coast of the Korean Peninsula (Fig. 1). The collected data included wind speed and direction at $2 \mathrm{~m}$ above the sea surface, photosynthetically active radiation (PAR) at about $2 \mathrm{~m}$ above the sea surface and at a depth of $10 \mathrm{~m}$, temperature and salinity at five depths $(5,20,40,60$ and $110 \mathrm{~m})$, current vertical profiles with an interval (bin size) of $4 \mathrm{~m}$ (uppermost bin corresponds to $5 \mathrm{~m}$ depth) and sea surface temperature (SST), salinity (SSS), dissolved oxygen (DO) and chlorophyll fluorescence (CF) measured by a Water Quality Monitor (WQM) at a depth of about $1 \mathrm{~m}$. Details on the technical design, improvements and early-phase operations of ESROB have been described previously (Nam et al., 2005). In the present study, we used data collected for $\sim 3$ years, from April 2011 to December 2013, with an emphasis on the three summer periods (JJAS) when the poleward alongshore current (showing a general width of up to about $40 \mathrm{~km}$ ) averaged over 6 years reversed to an equatorward direction (Park et al., 2016).

The $\mathrm{CF}$ as a factory-calibrated $\mathrm{Chl} a$ concentration in units of $\mu \mathrm{g} \mathrm{L}^{-1}$ following the manufacturer's (WET Lab) instructions always needs calibration with in situ measurements owing to long-term sensor drift and the fact that different $\mathrm{Chl} a$ concentrations may yield the same fluorescence energy (Longhurst et al., 1989). Four cruises were conducted in July and October 2011, April 2012 and July 2013 to collect in situ water samples for Chl $a$ and in situ sensor measurements for water temperature and salinity near the coast. A statistically significant correlation $\left(r^{2}=0.76, p<0.001\right)$ was found between the CF sensor values and in situ chlorophyll concentration derived from the spectrophotometer using acetone-

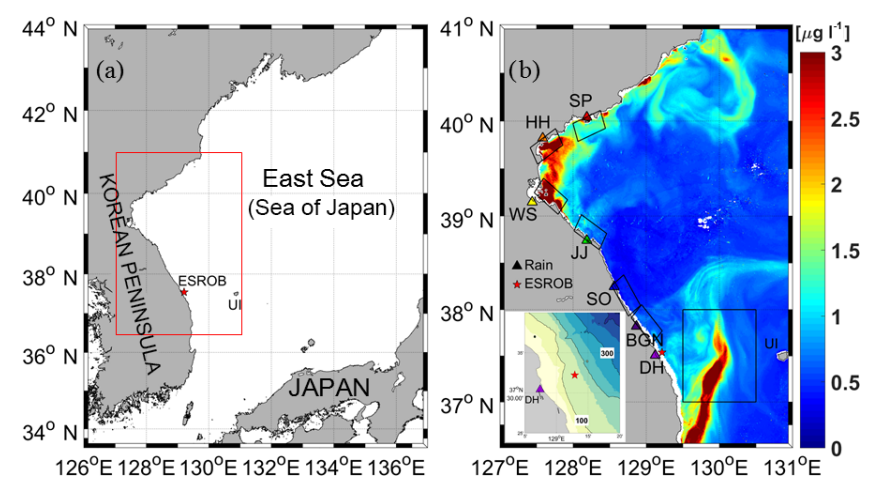

Figure 1. (a) Study area in the western East Sea (Sea of Japan). (b) A chlorophyll $a$ (Chl $a$ ) image from the geostationary ocean color satellite on 6 September 2012 in the area marked by a red box in (a). Black solid boxes denote the areas where the Chl $a$ and TSS are averaged. Locations of the rainfall stations along the east coast of the Korean Peninsula are marked by triangles (SP: SinPho, HH: HamHeung, WS: WonSan, JJ: JangJun, SO: Sockcho, BGN: BukGangNeung, DH: DongHae, rainbow-colored). The surface mooring (ESROB) is indicated by a red star in (b) with bottom topography in the lower left corner, where numbers denote water depth in meters (contour interval: $100 \mathrm{~m}$ ). Ulleung Island (UI) is located at $\sim 131^{\circ} \mathrm{E}$.

extracted Chl $a$ (Fig. 2a). In addition to the chlorophyll calibration, the concentrations of nitrate were analyzed simultaneously with 64 samples to determine the nitrate proxy based on the relationship between temperature and nitrate. Separately, to observe the fine-scale coastal SST and SSS distributions around the ESROB, in situ measurements using a small research vessel equipped with a thermosalinograph (SEB21, 10 s sampling interval) were conducted on 30 July 2013, a couple of days after heavy rainfall. Since non-photochemical quenching has a significant influence on the $\mathrm{CF}$ in response to changes in ambient light (Müller et al., 2001), particularly for a single-channel excitation $\mathrm{Chl} a$ fluorometer, the effects were corrected from the ESROB CF data following the methods described in Halverson and Pawlowicz (2013) before being calibrated with in situ water samples.

We used high-resolution daily data generated by the geostationary ocean color imager (GOCI) satellite (composited using eight images) to estimate surface $\mathrm{Chl} a$ distributions. The spatial resolution of the GOCI is $500 \mathrm{~m}$ and its altitude is 50 times higher $(35786 \mathrm{~km})$ than that of polar-orbiting ocean color satellites (Ryu et al., 2012). Chl $a$ concentration observed from the GOCI can be easily contaminated by total suspended sediment (TSS) and colored dissolved organic matter (CDOM) in the coastal regions (Ryu et al., 2012). Thus, the GOCI Chl $a$ was calculated through software modules of the GOCI Data Processing System (GDPS, described in Han et al., 2010 and Ryu et al., 2012) by applying a correction algorithm for the TSS and CDOM, as well as by minimizing the contaminating effects of cloud, sea fog and aerosols (level 1B). Nevertheless, relationships 

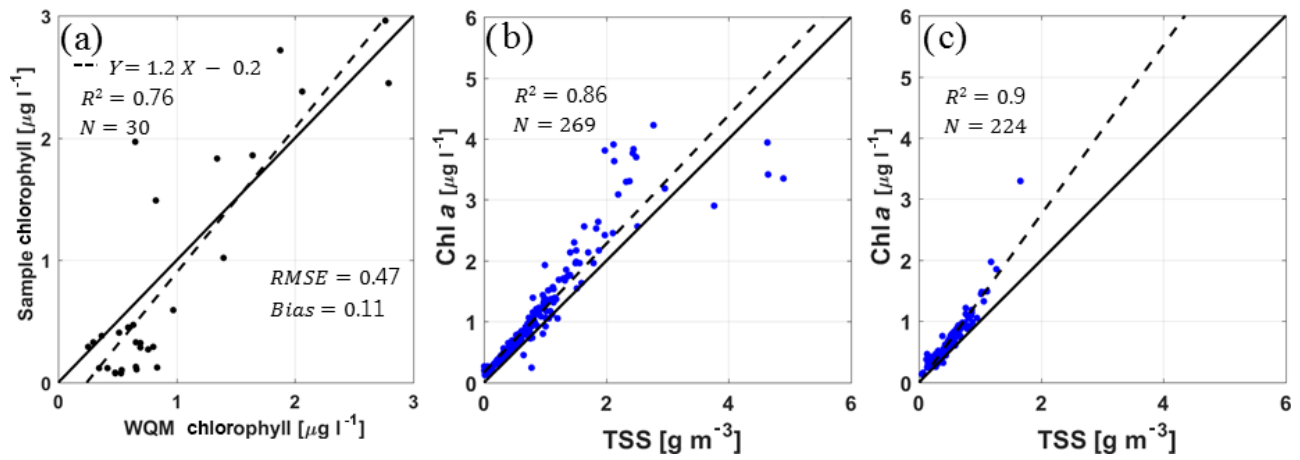

Figure 2. Results of cross-correlation $\left(R^{2}\right.$ : correlation coefficient) and linear regression analyses (dashed lines) between (a) chlorophyll fluorescence measured by the ESROB WQM and absolute chlorophyll concentration obtained from in situ water samples, and between TSS and GOCI chlorophyll $a$ concentration for (b) the areas along and near the east coast of the Korean Peninsula and (c) area off the coast between DH and UI. The water samples (N: sample number) were collected in July and October 2011 and April 2012.

between the GOCI Chl $a$ and TSS in coastal and offshore areas in Fig. 1 were compared with a linear regression to determine the Chl $a$ in the coastal region (Fig. 2b, c). Results exhibited that the higher the value, the wider the scatter. Despite the fact that the absolute value of Chl $a$ can be overestimated at high TSS (Kim et al., 2016), this indicates that the GOCI Chl $a$ in this area is still useful for understanding the variation in Chl $a$ spatial distribution because the horizontal pattern of Chl $a$ is realistic. Satellite-altimeter-derived sea surface height (SSH) products corrected using coastal tide-gauge sea-level data along the east coast of the Korean Peninsula (Choi et al., 2012) were used to examine surface geostrophic currents around and offshore of the ESROB in the summer of 2013. Precipitation data (provided by the Korea Meteorological Administration, KMA) were also used to compare the bloom timings with those of heavy rainfall in summer. Precipitation $\left(\mathrm{mm} \mathrm{day}^{-1}\right)$ was recorded every $3 \mathrm{~h}$ during the summers of 2011, 2012 and 2013 at stations along the coast (SP: SinPho, HH: HamHeung, WS: WonSan, JJ: JangJun, SO: Sockcho, BGN: BukGangNeung, DH: Dong$\mathrm{Hae}$ ), and the data were proxied as freshwater discharges from several small rivers into the East Sea (Fig. 1) without available data for freshwater discharges along the northern coast of the Korean Peninsula.

Current and wind vectors were corrected for local magnetic deviation, decomposed into alongshore and cross-shore components rotating counterclockwise from the north by $30^{\circ}$. Wind stresses have been calculated following $\boldsymbol{\tau}=$ $\rho_{\mathrm{a}} C_{\mathrm{D}}|W| \boldsymbol{W}\left(\rho_{\mathrm{a}}\right.$ : air density, $C_{\mathrm{D}}$ : drag coefficient, $\boldsymbol{W}$ : wind), and alongshore and cross-shore components of current $\left(V_{\mathrm{a}}\right.$ and $\left.U_{\mathrm{c}}\right)$ and wind stress $\left(\mathrm{WS}_{\mathrm{a}}\right.$ and $\mathrm{WS}_{\mathrm{c}}$ ) are expressed by the coordinate transformation, respectively (Large and Pond, 1981). All variables were low-pass-filtered with the half power centered at $40 \mathrm{~h}$.

\section{Results}

\subsection{Climatological CF variations}

Annual cycles of wind stress $\left(\mathrm{WS}_{\mathrm{a}}, \mathrm{WS}_{\mathrm{c}}\right)$, surface CF, SST, SSS, surface DO and surface current $\left(\left(V_{\mathrm{a}}, U_{\mathrm{c}}\right)\right.$ at the uppermost bin) observed at ESROB were obtained by climatologically averaging monthly mean values over the 3 years from 2011 to 2013, which showed significant summertime CF enhancements (in addition to two well-documented blooms in spring and fall), weakened wind forcing, increased SST, decreased SSS, oversaturated surface DO (though absolute DO decreased) and strengthened equatorward $\left(V_{\mathrm{a}}<0\right)$ surface currents (Fig. 3). The CF enhancements during the summer with significantly high concentrations $>1 \mu \mathrm{g} \mathrm{L}^{-1}$ in July, accompanied by decreased SSS (abruptly decreased from June to July) and strengthened equatorward currents (maximum speed of $15 \mathrm{~cm} \mathrm{~s}^{-1}$ in July), implied high Chl $a$ and lowsalinity water of northern origin. Although absolute DO decreased with increasing SST, the surface water was oversaturated for most of the summer, implying a significant role of surface bioactivity. Weak poleward $\left(V_{\mathrm{a}}>0\right.$ and $\left.U_{\mathrm{a}} \sim 0\right)$ surface currents were observed throughout the year, except in summer, when strong equatorward $\left(V_{\mathrm{a}}<0\right.$ and $\left.U_{\mathrm{a}} \sim 0\right)$ currents prevailed (Park et al., 2016).

\subsection{CF events observed in summers of 2011, 2012 and 2013}

In the summers of 2011, 2012 and 2013, 10 bloom events (E01-E10) were identified by the surface CF being significantly enhanced over a considerable period, i.e., days to weeks (Fig. 4, Table 1). The CF bloom events were defined as the period during which $\mathrm{CF}>1.0 \mu \mathrm{g} \mathrm{L}^{-1}$. Then, among the events, we selected only those during which the duration of $\mathrm{CF}>2.0 \mu \mathrm{g} \mathrm{L}^{-1}$ was longer than 1 day as the final events. The summer bloom event lasted for several days to weeks, which is shorter than the typical duration of spring 


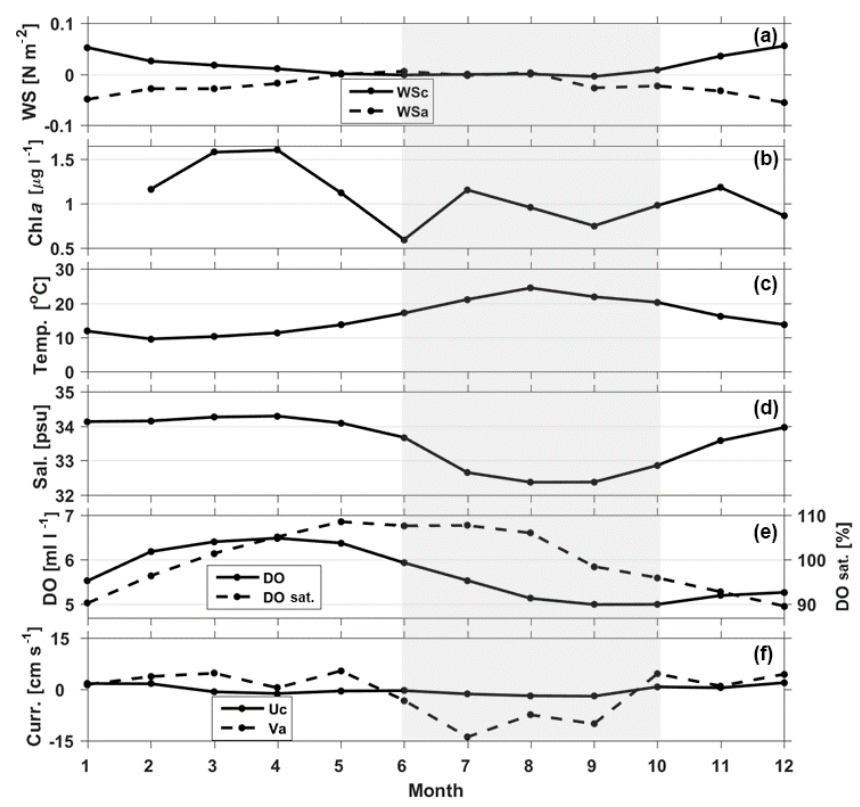

Figure 3. Climatology for (a) alongshore and cross-shore components of wind stress, (b) chlorophyll fluorescence, (c) water temperature, (d) salinity, (e) dissolved oxygen in both $\mathrm{mL} \mathrm{L}^{-1}$ and percent saturation, and (f) alongshore and cross-shore components of surface $(\sim 5 \mathrm{~m})$ current constructed using ESROB data collected in 3 years from 2011 to 2013. Summer season (JJAS) is shaded.

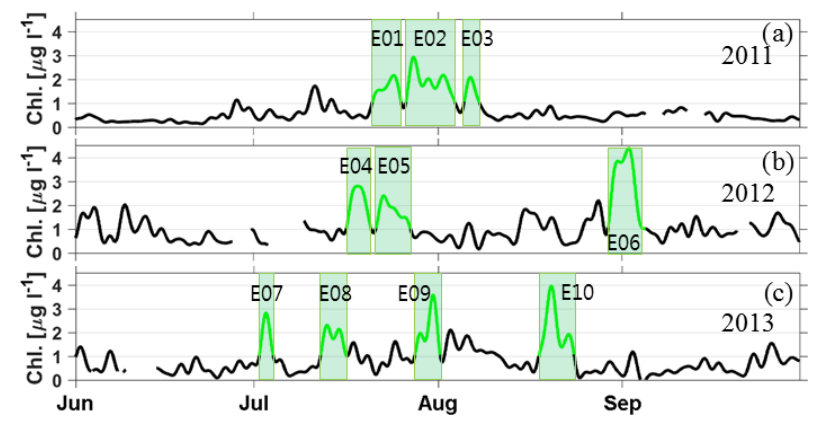

Figure 4. Time series of low-pass-filtered (cutoff period of $40 \mathrm{~h}$ ) chlorophyll fluorescence observed at ESROB during the three summers (JJAS) of (a) 2011, (b) 2012 and (c) 2013. The episodic bloom events are shaded in green and labeled E01 to E10.

and fall blooms. Six events, three in each year (E01-E03 and E04-E06), were identified in the summers of 2011 and 2012, whereas four (E07-E10) occurred in 2013 (Fig. 4). The average SST, SSS and CF for the duration of each event are listed in Table 1.

During the CF events in the summer of 2011 (E01-E03), low SSS was observed at ESROB several days to a week after remarkable wind forcing and heavy rainfall (maximum of $160 \mathrm{~mm} \mathrm{day}^{-1}$ during E02) at upstream stations, accompanying enhanced equatorward currents (Fig. 5a, c, e and f). Two typhoons (Maon and Muifa), yielding a maximum wind stress of $0.25 \mathrm{~N} \mathrm{~m}^{-2}$, passed through the region during the CF bloom events, inducing strong equatorward (before E01) and poleward (after E03) wind stresses (arrows labeled M1 and M2 in Fig. 5b) and implying downwelling (before E01) and upwelling (after E03) in the vicinity of ESROB. Interestingly, the equatorward (poleward) wind stress may strengthen equatorward (poleward) and onshore (offshore) surface currents. Indeed, strong equatorward currents were observed up to 2 days after the peak wind forcing immediately before $\mathrm{E} 01$, whereas the equatorward currents were markedly weakened by the poleward wind stress immediately after E03 (Fig. 5b, f).

Similarly, the CF events in the summer of 2012 were also accompanied by low or decreasing SSS several days to a week after heavy rainfall at upstream stations and equatorward currents (Fig. 6a, c, e and f). Three (Khanun, Bolaven and Tenbin) among the four typhoons in the summer affected the surface CF, SSS and surface currents during the events. Since typhoon Khanun drove poleward wind stress, the strong equatorward currents (a consequence of downwelling induced by the equatorward wind stress, as also testified by the rise in temperature at all levels before E04; Fig. 6d) which developed before and during most of E04 were weakened, and SSS increased to reduce the salinity stratification and decrease surface CF during E04 (arrow labeled $\mathrm{K}$ in Fig. 6b, c, e and f). After the typhoon passed, the surface CF increased again along with re-enhancing equatorward currents, re-stratifying salinity and decreasing SSS during E05 (Fig. 6c, e and f). Two typhoons (Bolaven and Tenbin) successively passed the area, and poleward (equatorward) wind stress imposed by Bolaven (Tenbin) induced an upwelling (downwelling) response with poleward (equatorward) and offshore (onshore) transport in the upper layer, decreasing (increasing) water temperature and increasing (decreasing) salinity in the whole column during E06. The poleward wind stress imposed by Bolaven induced well-mixed conditions with high SSS, low SST and strong poleward surface currents (arrow labeled B in Fig. 6b, c, d and f). However, the reversed wind stress imposed by the successive Tenbin typhoon resulted in decreasing SSS and increasing SST, weakening the poleward surface current (strengthening equatorward surface current) and rapidly increasing surface $\mathrm{CF}$ (peak exceeding $4.5 \mu \mathrm{g} \mathrm{L}^{-1}$ ) (arrow labeled $\mathrm{T}$ in Fig. 6b, c, d, e and f).

Contrasting with the CF bloom events in the summers of 2011 and 2012, two of the four events (E07 and E10) in the summer of 2013 did not follow heavy enough rainfall at the upstream stations nor equatorward currents (Fig. 7a, f). Typical heavy rainfall and enhanced equatorward surface currents preceded low SSS and high surface CF during the other two events (E08 and E09) only (Fig. 7a, f). Unlike typical events, the SSS remained high and SST temporally decreased (negative anomaly) during E07 (Fig. 7c and d), whereas relatively high SST and low SSS were observed during E10 (Fig. 7c, d). Contrasting with the other 2 years, winds were mild, and 
Table 1. Sea surface temperature (SST) in ${ }^{\circ} \mathrm{C}$, sea surface salinity (SSS) in $\mathrm{g} \mathrm{kg}^{-1}$, chlorophyll $a$ fluorescence (CF) in $\mu \mathrm{g} \mathrm{L}-1$, duration in days and euphotic depth $\left(Z_{\mathrm{eu}}\right)$ in $\mathrm{m}$ during the E01-E10 observed from the surface mooring. NA: not available.

\begin{tabular}{|c|c|c|c|c|c|c|c|}
\hline & & SST & SSS & $\mathrm{CF}$ & (start and end dates) & Duration & $Z_{\mathrm{eu}}$ \\
\hline \multirow{4}{*}{2011} & E01 & 20.5 & 31.2 & & 1.65 (21-25 July) & 4.9 & NA \\
\hline & E02 & 22.3 & 30.9 & & .91 (26 July-3 August) & 8.3 & NA \\
\hline & E03 & 24.3 & 29.9 & & 1.61 (5-8 August) & 2.5 & NA \\
\hline & E04 & 21.4 & 32.9 & & 1.67 (16-20 July) & 3.5 & 22 \\
\hline \multirow{2}{*}{2012} & E05 & 22.8 & 32.8 & & 1.29 (21-27 July) & 5.8 & 20.6 \\
\hline & E06 & 18.1 & 33.4 & 2.35 & 9 August-5 September) & 6.4 & 16.8 \\
\hline \multirow{4}{*}{2013} & E07 & 16.1 & 34.1 & & 1.6 (1-4 July) & 2.3 & 17.8 \\
\hline & E08 & 21.2 & 33.2 & & 1.6 (12-16 July) & 4.4 & 15.7 \\
\hline & E09 & 25.0 & 32.1 & & 1.7 (28 July-1 August) & 4.3 & 12.7 \\
\hline & E10 & 26.7 & 31.9 & & 1.4 (18-23 August) & 5.9 & 15.2 \\
\hline
\end{tabular}

no typhoon passage was reported in the summer of 2013 (Fig. 7b).

\subsection{Surface CF distributions}

The equatorward advection of low-salinity, chlorophyll-rich plume water into the ESROB area along the coast was confirmed from a series of daily composite GOCI Chl $a$ only when clear images containing few clouds were available. One example presented here is from four images continuously available from 24 to 27 July 2013, before E09 (Fig. 8ad). A high surface $\mathrm{CF}$ zone in the northern area (e.g., off the SP, HH and WS sites; Fig. 1) was separated from that in the southern area (e.g., between the coast and Ulleung Island (UI); Fig. 1) following the poleward current - the East Korea Warm Current (EKWC) - whereas a more coastal branch extended equatorward with time near the coast (Fig. 8a-d) after the heavy rainfall of 19-24 July (Fig. 7a). The high CF plume water was elongated and reached JJ by 24 July, SO by $25-$ 26 July, and most probably hit ESROB by 27 July (Fig. $8 \mathrm{~d}$ is cloudy, but salinity drops in Fig. 7), yielding the E09 event from 28 July to 1 August (Table 1, Fig. 7). The SST and SSS observed using the thermosalinograph on 30 July 2013 in the vicinity of ESROB consistently demonstrated wedge-shaped patterns with low SSS and high SST water confined near the coast and reaching farther south passing BGN (Fig. 8e, $\mathrm{f}$ ), confirming the equatorward advection of low-salinity and high CF surface water along the coast to ESROB. Consistent with this picture, the satellite-based surface geostrophic currents around and offshore of ESROB (not shown) and the alongshore currents observed at the upper depths of ESROB (e.g., Fig. 7f) were all equatorward during this period.

The patterns of surface CF distribution and geostrophic flow field on 3 July 2013 for E07 are shown in Fig. 9a and $\mathrm{b}$, whereby high $\mathrm{CF}$ was found inshore of the polewardflowing EKWC (its main axis is closer to UI than the high $\mathrm{CF}$ area) and within the cyclonic circulation around ESROB (area of relatively low SSH). Onshore currents prevailed be- tween BGN and DH, associated with the cyclonic circulation (Fig. 9b), potentially yielding onshore advection of high CF offshore water of southern origin into the coastal zone near ESROB during E07 (Fig. 9d). Similarly, although clear images were not available at that time, the geostrophic flow field on 21 August 2013 for E10 is shown in Fig. 9c, whereby offshore currents were found to prevail near the coastal zone and near DH and ESROB, as well as equatorward currents immediately to the north. The offshore advection of coastal plume water of northern origin presumably having low salinity, high temperature and high CF (see Fig. 7, but also other similar events, as in Fig. 1 or Fig. 8) may have enhanced the surface $\mathrm{CF}$ at ESROB during E10 (Fig. 9e).

\section{Discussion}

\subsection{Horizontal advection}

The low-salinity chlorophyll-rich water originating from the northern coastal region often accompanying heavy rainfall is advected equatorward along the coast into the coastal zone in the vicinity of ESROB in summer, and is primarily responsible for most $(80 \%, 8$ out of 10$)$ of the CF events. The rate of $\mathrm{Chl} a$ change observed at ESROB is comparable with the rate estimated from the spatial Chl $a$ gradient and speed of equatorward advection. The equatorward advection distance of high Chl $a$ water is measured to be $\mathrm{d} y=100 \mathrm{~km}$ over 3 days (i.e., $\mathrm{d} t$ ) with $\mathrm{Chl} a$ change (difference between $\mathrm{Chl} a$ at the plume source and the initially oligotrophic water at ESROB) of about $2.5 \mu \mathrm{g} \mathrm{L}^{-1}$ (i.e., dChl) from the series of four daily composites of GOCI Chl $a$ collected during 24-27 July 2013 before E09 (Fig. 8a-d). With an advective speed of $0.4 \mathrm{~m} \mathrm{~s}^{-1}$ $\left(=100 \mathrm{~km} 3 /\right.$ day $\left.^{-1}\right)$, this yields a rate of Chl $a$ change of $0.86 \mu \mathrm{g} \mathrm{L}^{-1} \mathrm{day}^{-1}\left(=0.4 \mathrm{~m} \mathrm{~s}^{-1} \times 2.5 \mu \mathrm{g} \mathrm{L}-1 / 100 \mathrm{~km}^{-1}\right)$ owing to the alongshore advection ( $v \partial \mathrm{Chl} a / \partial y$ ), which is consistent with the observed rate ( $\partial \mathrm{Chl} a / \partial t$, where $\mathrm{dChl}$ was estimated from the ESROB measurements and $\mathrm{d} t=1 \mathrm{~h}$ ) for 


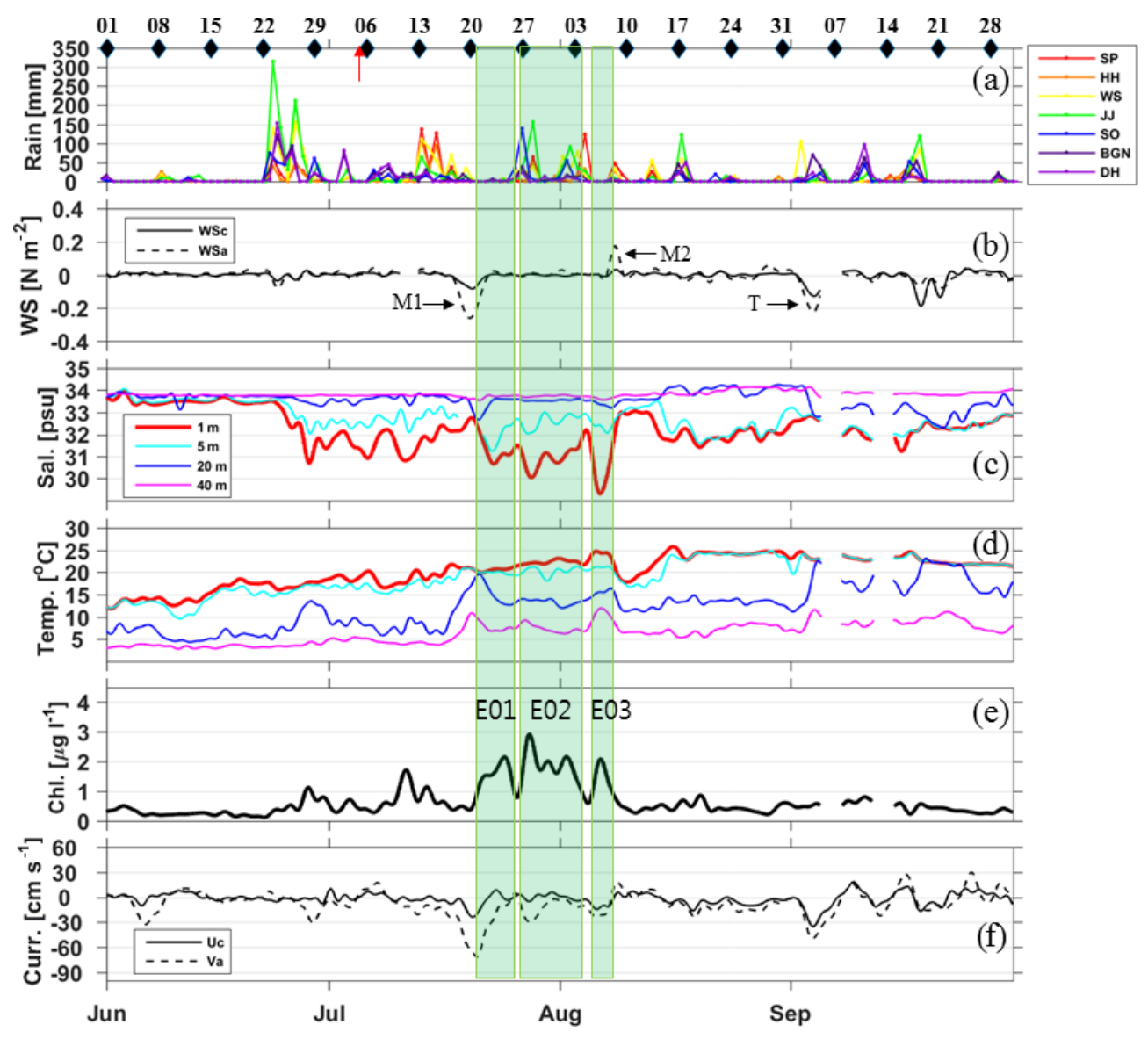

Figure 5. Time-series data collected in 2011 of (a) daily rainfall amounts observed at weather stations (SP: SinPho, HH: HamHeung, WS: WonSan, JJ: JangJun, SO: Sockcho, BGN: BukGangNeung, DH: DongHae) along the east coast of the Korean Peninsula, and (b) alongshore (solid) and cross-shore (dash) wind stresses, (c) salinities and (d) water temperatures observed at the surface (red), 5 (cyan), 20 (blue) and $40 \mathrm{~m}$ (pink), (e) surface CF and (f) alongshore (dashed) and cross-shore (solid) currents, observed at ESROB. The bloom events are labeled E01 to E03. In the top axis of (a), dates/times of the satellite-altimetry-derived surface geostrophic current map and geostationary satellite ocean color image (GOCI) are marked with black diamonds and a red arrow, respectively. Nearby passages of typhoons are indicated by black arrows in (b) (M1: Maon, M2: Muifa and T: Talas).

E09 (up to $1.26 \mu \mathrm{g} \mathrm{L}^{-1} \mathrm{day}^{-1}$ averaged over the period when $\partial \mathrm{Chl} a / \partial t>0$ ) and others (mean: $0.87 \mu \mathrm{g} \mathrm{L}^{-1} \mathrm{day}^{-1}$ ), supporting the fact that the alongshore advection plays a primary role in $\mathrm{CF}$ variability near the coast. The distribution and temporal evolution of SSS observed in 30 July 2013 implies that the low-salinity plume water (SSS $<29 \mathrm{~g} \mathrm{~kg}^{-1}$ found in the northern coastal area; Fig. 8e) is mixed with saline offshore water while advected equatorward, yielding slightly higher $\left(>31 \mathrm{~g} \mathrm{~kg}^{-1}\right)$ SSS at ESROB. These findings are similar to those of bloom events with a rate of $\mathrm{CF}$ change (2-4 $\mu \mathrm{g} \mathrm{L}^{-1}$ day $^{-1}$, estimated from Fig. 11 of Halverson and Pawlowicz, 2013) controlled by the advection of low SSS and high CF plume water in other coastal systems (Halverson and Pawlowicz, 2013).

In contrast to E09, the high surface CF observed during E07 is not explained by equatorward advection of lowsalinity chlorophyll-rich water originating from the northern coastal region, but potentially by the onshore advec- tion of high CF water of southern origin advected via the EKWC. Hyun et al. (2009) demonstrated that the highest primary productivity in the southwestern East Sea is induced by the transport of high CF water originated from upwelling of nutrient-rich water along the southern east coast of the Korean Peninsula. The high CF water may affect the productivity near the mid-east coast of the Korean Peninsula as advected by the EKWC and its meanders, particularly on the western or coastal side of the front formed by the EKWC. Indeed, a rate of cross-shore Chl $a$ change around ESROB from the surface CF distribution observed during E07 (Fig. 9a) is roughly $0.1 \mu \mathrm{g} \mathrm{L}^{-1} \mathrm{~km}^{-1}$ ( $\mathrm{dChl}=$ $1.0 \mu \mathrm{g} \mathrm{L}^{-1}$ and $\mathrm{d} x=10 \mathrm{~km}$ ) and a rate of Chl $a$ change by cross-shore advection ( $u \partial \mathrm{Chl} a / \partial x)$ is estimated to be $0.86 \mu \mathrm{g} \mathrm{L}^{-1} \mathrm{day}^{-1}\left(=0.1 \mathrm{~m} \mathrm{~s}^{-1} \times 1.0 \mu \mathrm{g} \mathrm{L}^{-1} / 10 \mathrm{~km}^{-1}\right)$ with a cross-shore velocity of $0.1 \mathrm{~m} \mathrm{~s}^{-1}$ (estimated from the ESROB measurements), which supports this assertion, demonstrating the influence of the high $\mathrm{CF}$ region offshore on the 


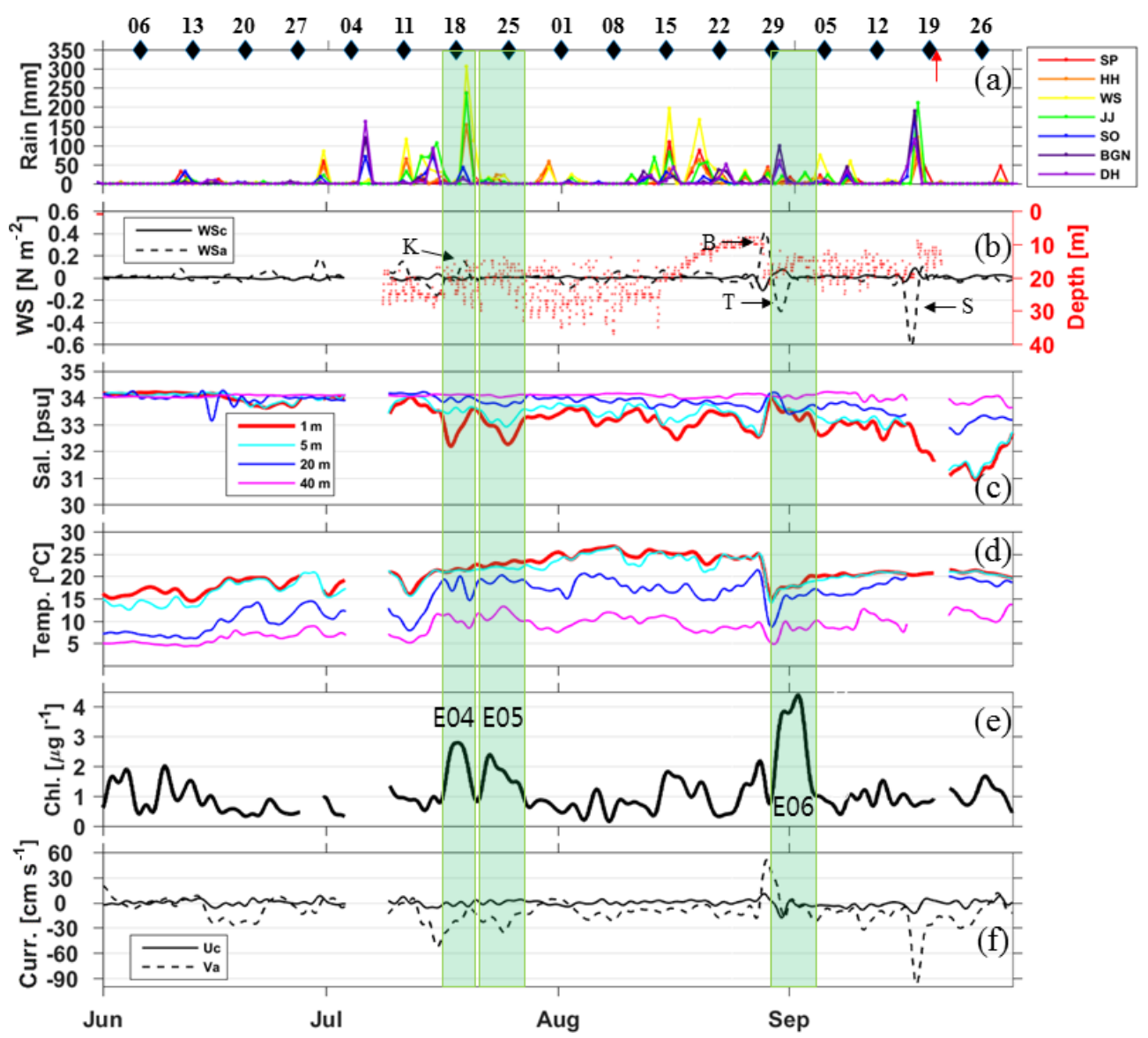

Figure 6. Same as Fig. 5, but for the 2012 bloom events labeled E04 to E06, and four typhoons (K: Khanun, T: Tenbin, B: Bolaven, S: Sanba). Euphotic depths ( $Z_{\mathrm{eu}}$, red dots) derived from two PAR sensors attached to the ESROB are superimposed in (b).

ESROB site (Fig. 9a, d). Onshore advection of the high CF water originated from the upwelling of nutrient-rich water along the coast accounts for half of the CF change during the event (up to $1.60 \mu \mathrm{g} \mathrm{L}^{-1}$ day $^{-1}$ averaged over the E07 when $\partial \mathrm{Chl} a / \partial t>0)$ observed at ESROB during E07 (Fig. 7). Conversely, offshore advection of high CF coastal plume water of northern origin, similarly to E09 and other northern water advection events, may also be significant, as is also the case for the E10 bloom. Based on previous research conducted in other coastal systems, E10 is similar to results on temporal and spatial variations of CDOM, CF and primary productivity by cross-shore (onshore and/or offshore) advection of high SST and high CF plume water associated with local circulations (Brzezinski and Washburn, 2011; Warrick et al., 2007). Thus, cross-shore advection of low SSS and high CF water associated with ambient circulation plays an equally significant role in shaping and triggering bloom events in the coastal area.

\subsection{Other mechanisms}

The high CF events observed at ESROB are not local blooms triggered by either nutrients or light availability. The upward vertical flux of nitrate into the euphotic zone at Huntington Beach, southern California, shows how vertical nutrient supply triggers local chlorophyll blooms (Omand et al., 2012). Omand et al. (2012) demonstrated that each episodic bloom was preceded by a vertical nitrate flux event $6-10$ days earlier using nitrate concentrations estimated from a temperature proxy. Relationships between nitrate and temperature and between nitrate and salinity observed from the surveys in July and October 2011 and April 2012 are not significantly different from each other, and the vertical nitrate fluxes were estimated by the temperature proxy to discuss the potential role of nitrate in triggering the episodic blooms. However, both advective and turbulent nitrate fluxes estimated using a nitrate proxy utilized from temperature measurements (Fig. 10) did not account for the observed CF blooms (not shown). Moreover, local blooms triggered by nutrients supplied by equatorward advection is not supported by surface CF distribution (decreasing equatorward) during 24-27 July 2013 


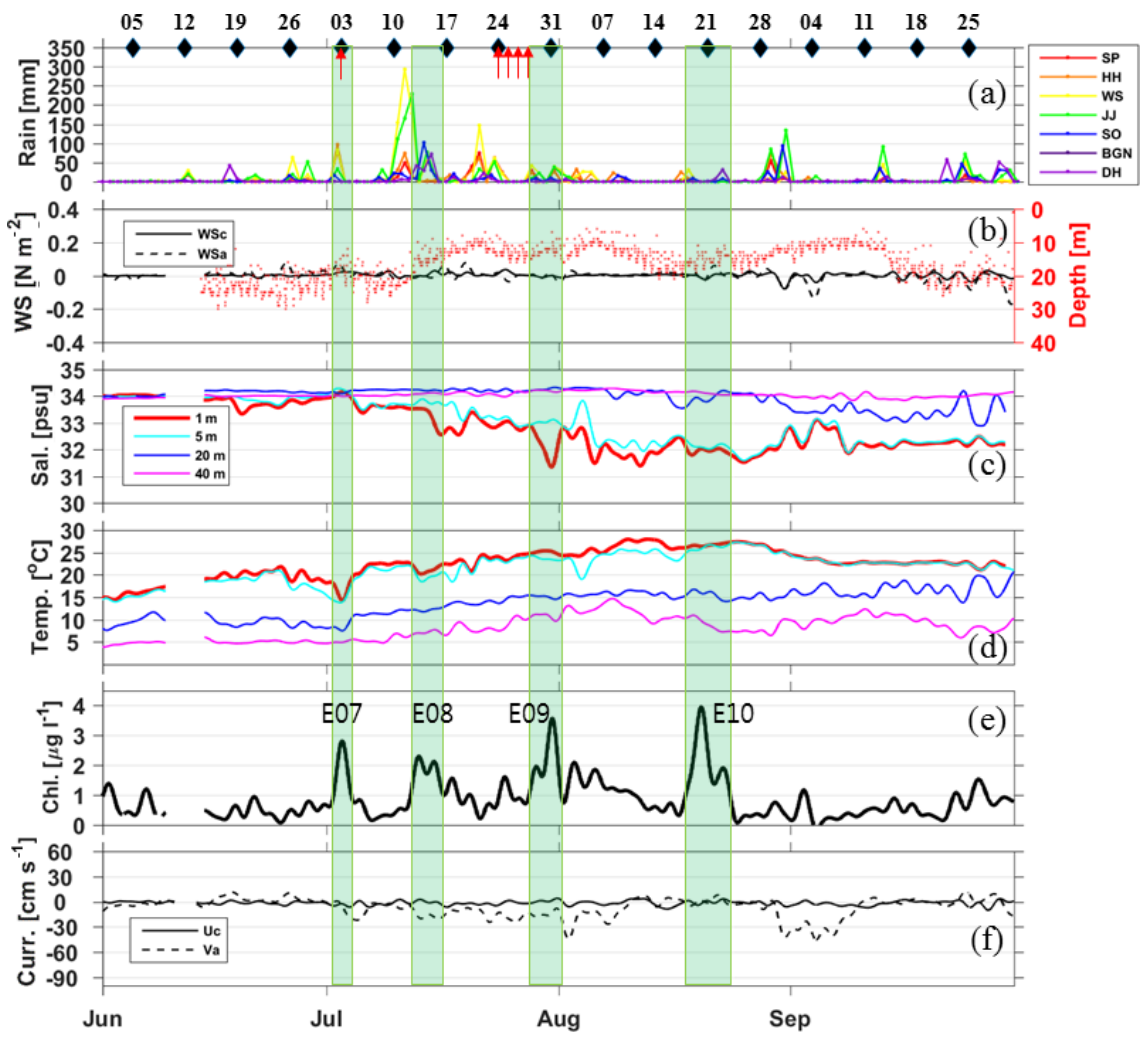

Figure 7. Same as Fig. 6 but for the 2013 bloom events labeled E07 to E10, and no typhoon occurrence.
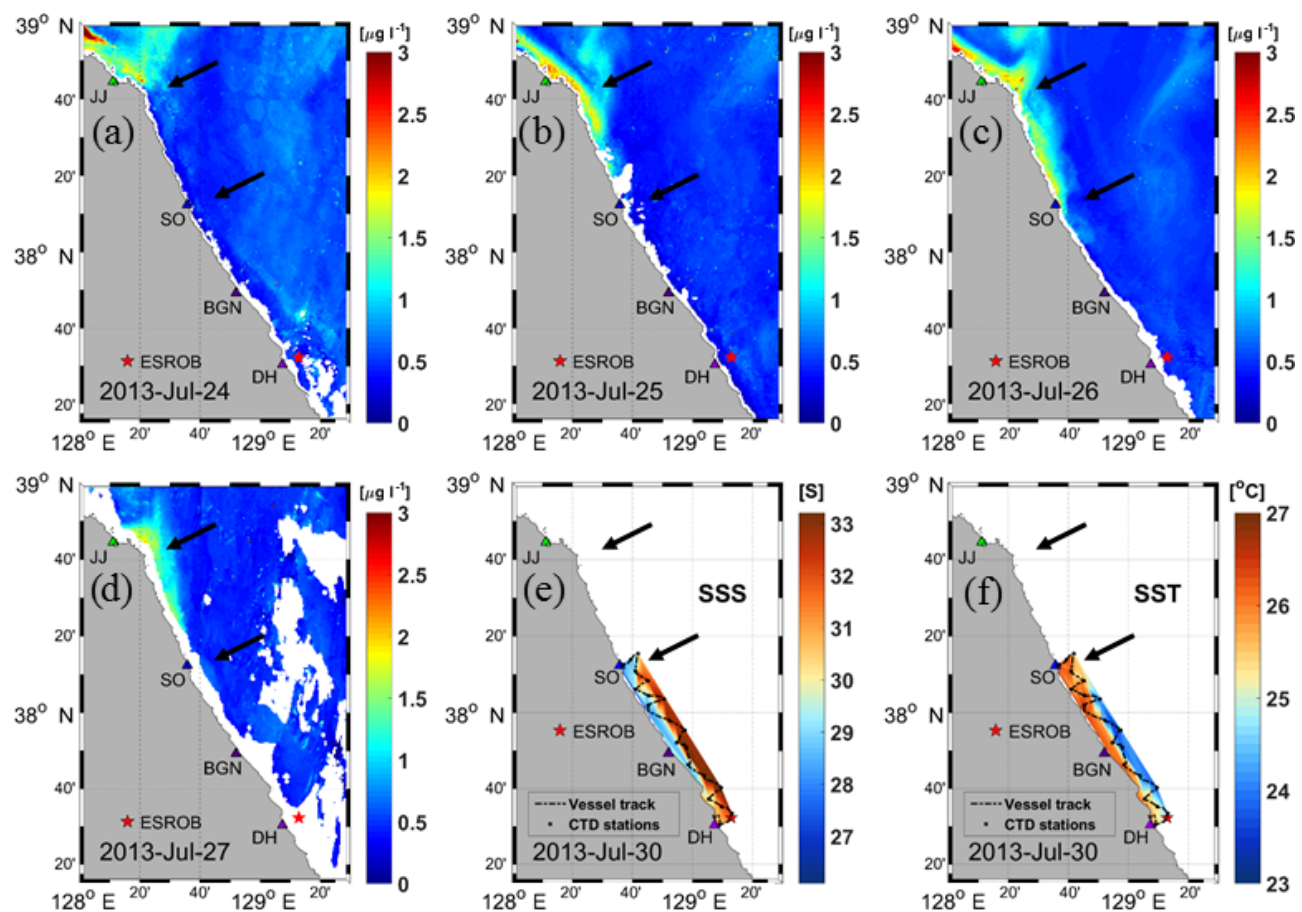

Figure 8. (a)-(d) Daily series of GOCI indicating surface chlorophyll $a$ distributions from 24 to 27 July 2013. Surface distributions of in situ (e) salinity and (f) temperature (dashed lines: ship tracks; dots: CTD stations) in 30 July 2013 a couple of days after heavy rainfall in the region. Two black arrows in each panel point to the same locations in the vicinity of JJ (JangJun) and SO (Sockcho). 

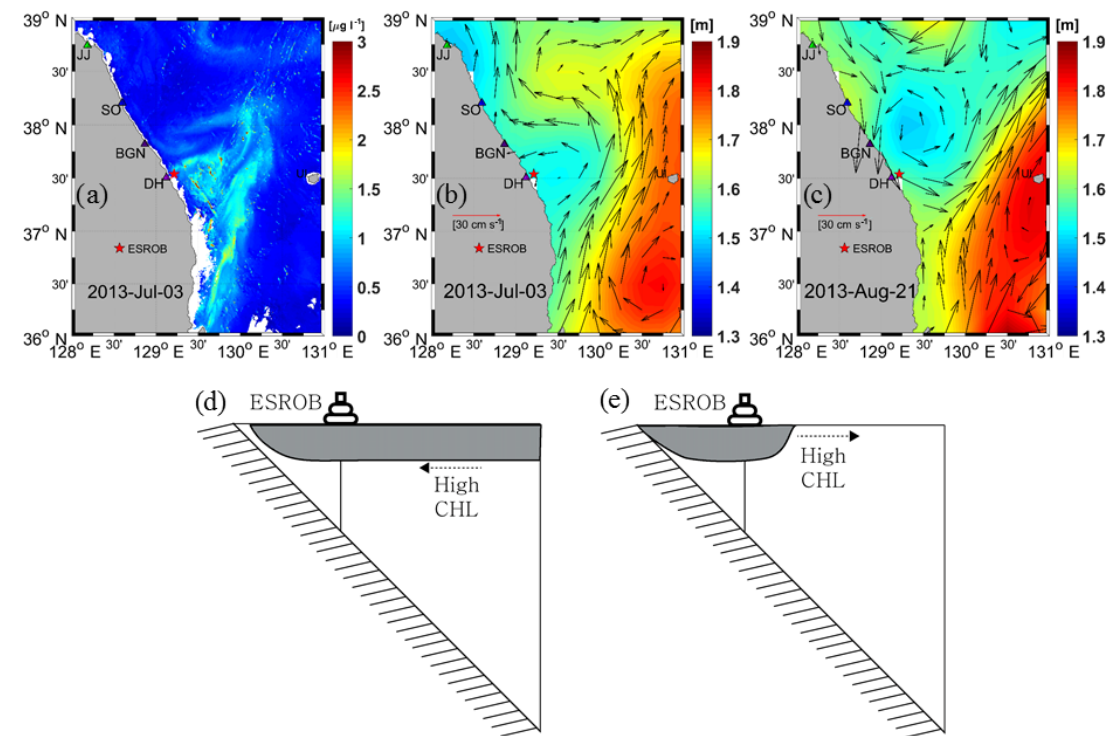

(e) ESROB 8

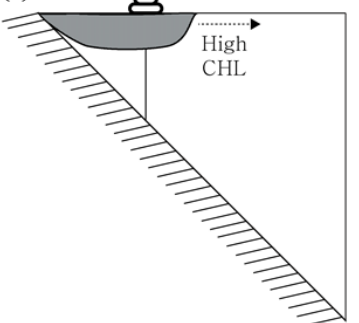

Figure 9. Distributions of (a) daily composite of chlorophyll $a$ concentration in 3 July 2013, obtained from the GOCI, and satellite-altimetryderived surface geostrophic currents in (b) 3 July and (c) 21 August 2013. Schematics for (d) on-shore and (e) off-shore advection of high CF surface water for 3 July (E07) and 21 August 2013 (E10).

(Fig. 8). Although some episodic CF blooms (E01 and E06) are preceded by flux peaks with a typical time lag of $4-12$ days, most events are not directly linked to the variability in vertical nitrate fluxes, suggesting only minor roles of nutrient flux in shaping $C F$ variability observed at ESROB in summer.

Time series of the euphotic zone depth $\left(Z_{\text {eu }}\right)$ were compared with the other time-series data recorded at ESROB to examine the effects of light adaptation on the bloom events, using the data collected using two PAR sensors available for 2012 and 2013 (Figs. 6 and 7). Basically, the average for the E04 to E10 bloom periods, $Z_{\mathrm{eu}}=18 \mathrm{~m}$, was deeper than $10.5 \mathrm{~m}$, which is $Z_{\text {eu }}$ averaged over the two whole summer periods (JJAS), indicating that the light environment was favorable, at least for the retaining and increasing of the $\mathrm{CF}$ bloom observed at ESROB. A $Z_{\text {eu }}$ of $20 \mathrm{~m}$ obtained by averaging over the three bloom events (E04-E06) in 2012 was deeper than that $\left(Z_{\mathrm{eu}}=15 \mathrm{~m}\right.$ for E07-E10) in 2013, supporting more favorable CF bloom conditions in 2012 than 2013. Correspondingly, CF of $1.8 \mu \mathrm{g} \mathrm{L}{ }^{-1}$ averaged over E04-E06 in 2012 was higher than that in $2013\left(\sim 1.6 \mu g \mathrm{~L}^{-1}\right.$ for E07E10). Our results for the deeper $Z_{\text {eu }}$, with higher $C F$ in summer 2012 than summer 2013, are consistent with those in other systems (e.g., Mississippi River coastal system), in which light attenuation plays a significant role in increasing phytoplankton biomass and productivity variation (Lehrter et al., 2009). However, the CF changes among the individual events do not necessarily follow $Z_{\text {eu }}$ variations (Table 1 ), suggesting a minor role of light availability in shaping the $\mathrm{CF}$ variability observed at ESROB.

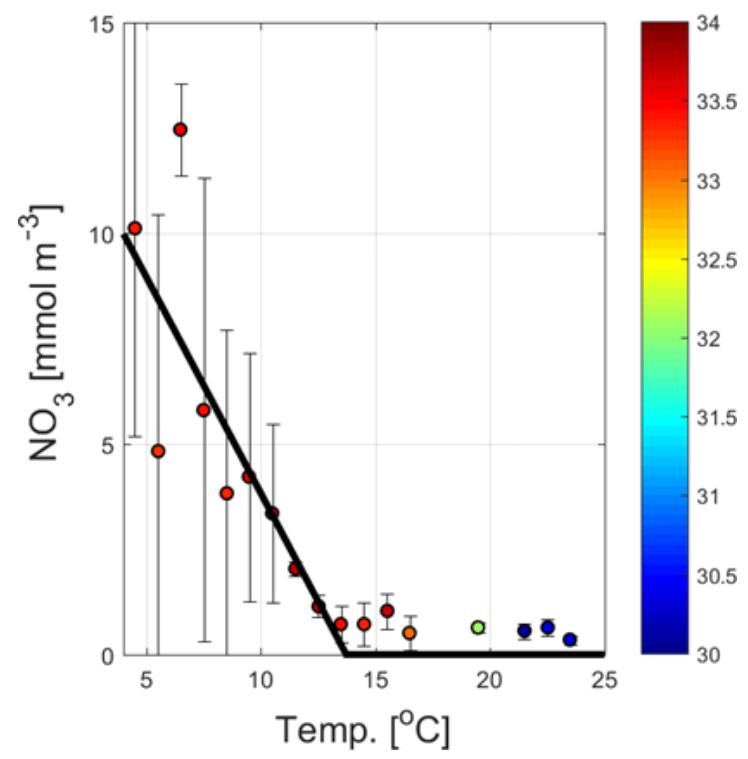

Figure 10. A linear fit (bold line) between temperature (Temp.) and nitrate $\left(\mathrm{NO}_{3}\right)$ for Temp $<14.0^{\circ} \mathrm{C}\left(\mathrm{NO}_{3}=0\right.$ for Temp $\left.>14.0^{\circ} \mathrm{C}\right)$ to observations near the east coast of the Korean Peninsula in the summers of 2011 and 2012. Standard deviations for nitrate and absolute salinity in $\mathrm{g} / \mathrm{kg}$ are shown with vertical bars and colors (color bar on the right), respectively.

\subsection{Interannual variations}

The CF bloom events near the coast can vary interannually depending on the passage of typhoons. Five typhoons that passed through this area were associated with the $\mathrm{CF}$ 
bloom events for two summers (2011 and 2012), and there was no typhoon affecting the CF bloom events in summer 2013. Both strong wind forcing and intensive rainfall associated with typhoon passage nearby determine how the plume water is advected to and around ESROB, which varies from year to year. In 2011, for example, the CF enhancement (E01) was accompanied by the passage of MAON (equatorward wind stress and current) through the area south of ESROB, whereas E03 ended with the passage of MUIFA (poleward wind stress and current) passing through the area north of ESROB (Fig. 5b). Similarly, surface CF decreased (increased) with the passages of typhoons KHANUN and BOLAVEN (TENBIIN) through the area north (south) of ESROB (Fig. 6b). Without any typhoon passage in the summer of 2013, only half of the CF events could be explained by the alongshore advection contrasting with those in the other 2 years (Fig. 7b). Thus, the primary productivity in the area is possibly affected severely by interannual variations of typhoon-induced alongshore advection.

Remote wind forcing significantly affecting summertime equatorward currents near the coast via equatorward propagating coastal trapped waves (CTWs) varied in the summers of 2011, 2012 and 2013 (Park and Nam, 2018, in revision). The CTWs generated off the Russian coast $(\sim 1000 \mathrm{~km}$ from ESROB) changed equatorward currents at the location of ESROB to yield more equatorward advection in summer 2011 and 2012 and more poleward advection in summer 2013 of low-salinity plume water near the coast (Park and Nam, 2018, in revision). These results may be relevant to more CF bloom events explained by equatorward advection of plume water of northern origin in summer 2011 and 2012 than summer 2013 (six of six events vs. two of four events). Therefore, interannual variations of alongshore advection and surface $\mathrm{CF}$ blooms near the coast are possibly affected by the CTWs propagating equatorward from the Russian coast, where wind forcing varies considerably to generate CTWs. Park and Nam (2018, in revision) also quantified the role of the EKWC on the alongshore current variability near the coast, which reveals a reduced EKWC impact and more equatorward currents near the coast during summer 2011 and 2013 than in summer 2012. Although this is inconsistent with fewer $\mathrm{CF}$ bloom events explained by the equatorward advection of plume water of northern origin in summer 2013, cross-shore advection of high CF water of either northern (E10) or southern origin (E07) are possibly associated with EKWC recirculation based on the patterns of surface geostrophic currents (Fig. 9).

\section{Concluding remarks}

The low-salinity chlorophyll-rich water originating from the northern coast of the Korean Peninsula accompanying heavy rainfall is often advected equatorward along the coast in summer, resulting in high surface $\mathrm{CF}$ events near the mid-east coast of the Korean Peninsula. Alongshore advection of high CF waters is primarily responsible for most $(80 \%, 8$ of 10$)$ of the $\mathrm{CF}$ events, which confirms that the bloom events are possibly controlled by the advection of low SSS and high $\mathrm{CF}$ plume water in summer. In contrast to the bloom events associated with alongshore advection, the high surface CF observed during E07 is possibly explained by the onshore advection of high CF water of southern origin advected by the poleward-flowing EKWC. Similarly, offshore advection of high CF coastal plume water of northern origin may be significant, as in the case of E10. Therefore, the equatorward and cross-shore advection of chlorophyll-rich plume water with decreasing SSS plays a primary role in the high productivity near the east coast of the Korean Peninsula in summer. Summertime CF near the coast varies interannually as the horizontal advection varies significantly, interannually associated with typhoon passages nearby, CTWs generated from the Russian coast and influence of the EKWC, which should be addressed using long-term time-series data in the future.

Data availability. All data are available upon request to the authors.

Author contributions. This work was conceptualized and funding was secured by SHN and YTS. In situ measurements were designed by SHN and YTS and performed by YTS and JHP with equipment provided by SHN and YTS. Data were analyzed by YTS and JHP. The manuscript was written by YTS and SHN and edited by YTS, SHN and JHP. All authors have approved the final article.

Competing interests. The authors declare that they have no conflict of interest.

Acknowledgements. We thank Kyung-Il Chang for his helpful comments to improve the original version of this paper. GOCI, precipitation and satellite-altimetry-derived sea surface height data were provided by the KIOST, KMA and AVISO, respectively. This research was supported by the Basic Science Research Program through the National Research Foundation of Korea (NRF) funded by the Ministry of Education (no. 2017R1D1A1B03035958 and NRF-2015R1D1A1A02062252) and was a part of the project entitled "Deep Water Circulation and Material Cycling in the East Sea", funded by the Ministry of Oceans and Fisheries, Republic of Korea. This work is partly supported by the Agency for Defense Development (UD170006DD), Republic of Korea.

Edited by: Emilio Marañón

Reviewed by: two anonymous referees 


\section{References}

Bae, D. H., Jung, I. W., and Chang, H.: Long-term trend of precipitation and runoff in Korean river basins, Hydro. Proc., 22, 2644-2656, https://doi.org/10.1002/hyp.6861, 2008.

Brzezinski, M. A. and Washburn, L.: Phytoplankton primary productivity in the Santa Barbara Channel: Effects of wind-driven upwelling and mesoscale eddies, J. Geophys. Res., 116, C12013, https://doi.org/10.1029/2011jc007397, 2011.

Choi, B.-J., Byun, D.-S., and Lee, K.-H.: Satellite-altimeterderived East Sea aurface currents: Estimation, description and variability pattern, The Sea, 17, 225-242, https://doi.org/10.7850/jkso.2012.17.4.225, 2012.

Crespo, B. G., Figueiras, F. G., and Groom, S.: Role of across-shelf currents in the dynamics of harmful dinoflagellate blooms in the northwestern Iberian upwelling, Limnol. Oceanogr., 52, 26682678, https://doi.org/10.4319/lo.2007.52.6.2668, 2007.

Dai, M. H., Zhai, W. D., Cai, W. J., Callahan, J., Huang, B. Q., Shang, S. L., Huang, T., Li, X. L., Lu, Z. M., Chen, W. F., and Chen, Z. Z.: Effects of an estuarine plumeassociated bloom on the carbonate system in the lower reaches of the Pearl River estuary and the coastal zone of the northern South China Sea, Cont. Shelf Res., 28, 1416-1423, https://doi.org/10.1016/j.csr.2007.04.018, 2008.

Halverson, M. J. and Pawlowicz, R.: High-resolution observations of chlorophyll $a$ biomass from an instrumented ferry: Influence of the Fraser River plume from 2003 to 2006, Cont. Shelf Res., 59, 52-64, https://doi.org/10.1016/j.csr.2013.04.010, 2013.

Han, H.-J., Ryu, J.-H., and Ahn, Y.-H.: Development the Geostationary Ocean Color Imager (GOCI) Data Processing System (GDPS), K. J. Rem. Sens., 26, 239-249, 2010.

Hong, G.-H., Lee, D.-K., Yang, D.-B., Kim, Y. I., Park, J.H., and Park, C.-H.: Eddy- and wind-sustained moderate primary productivity in the temperate East Sea (Sea of Japan), Biogeosciences Discuss., 10, 10429-10458, https://doi.org/10.5194/bgd-10-10429-2013, 2013.

Hyun, J., Kim, D., Shin, C., Noh, J., Yang, E., Mok, J., Kim, S., Kim, H., and Yoo, S.: Enhanced phytoplankton and bacterioplankton production coupled to coastal upwelling and an anticyclonic eddy in the Ulleung basin, East Sea, Aquat. Microbial Ecol., 54, 45-54, https://doi.org/10.3354/ame01280, 2008.

Kang, J. H., Kim, W. S., Chang, K. I., and Noh, J. H.: Distribution of plankton related to the mesoscale physical structure within the surface mixed layer in the southwestern East Sea, Korea, J. Plankton Res., 26, 1515-1528, https://doi.org/10.1093/plankt/fbh140, 2004.

Kim, D., Yang, E. J., Kim, K. H., Shin, C. W., Park, J., Yoo, S., and Hyun, J. H.: Impact of an anticyclonic eddy on the summer nutrient and chlorophyll $a$ distributions in the Ulleung Basin, East Sea (Japan Sea), ICES J. Mar. Sci., 69, 23-29, https://doi.org/10.1093/icesjms/fsr178, 2011.

Kim, W., Moon, J.-E., Park, Y.-J., and Ishizaka, J.: Evaluation of chlorophyll retrievals from Geostationary Ocean Color Imager (GOCI) for the North-East Asian region, Rem. Sens. Environ., 184, 428-495, 2016.

Kong, G. S., Kim, K.-O., and Kim, S.-P.: Characteristics of the East Asian summer monsoon in the South Sea of Korea during the Little Ice Age, Quaternary Int., 286, 36-44, https://doi.org/10.1016/j.quaint.2012.07.022, 2013.
Large, W. G. and Pond, S.: Open Ocean Momentum Flux Measurement in Moderate to Strong Winds, J. Phys. Oceanogr., 11, 324 336, 1981.

Lehrter, J. C., Murrell, M. C., and Kurtz, J. C.: Interactions between freshwater input, light, and phytoplankton dynamics on the Louisiana continental shelf, Cont. Shelf Res., 29, 1861-1872, https://doi.org/10.1016/j.csr.2009.07.001, 2009.

Longhurst, A. R. and Harrison, W. G.: The biological pump: Profiles of plankton production and consumption in the upper ocean, Prog. Oceanogr., 22, 47-123, 1989.

Müller, P., Li, X., and Niyogi, K. K.: Non-Photochemical Quenching. A Response to Excess Light Energy, Plant Physiol., 125, 1558-1566, https://doi.org/10.1104/pp.125.4.1558, 2001.

Nam, S., Kim, G., Kim, K.-R., and Kim, K.: Application of Realtime Monitoring Buoy Systems for Physical and Biogeochemical Parameters in the Coastal Ocean around the Korean Peninsula, Mar. Technol. Soc. J., 39, 70-80, 2005.

Omand, M. M., Feddersen, F., Guza, R. T., and Franks, P. J. S.: Episodic vertical nutrient fluxes and nearshore phytoplankton blooms in Southern California, Limnol. Oceanogr., 57, 16731688, https://doi.org/10.4319/lo.2012.57.6.1673, 2012.

Park, J.-H., Chang, K.-I., and Nam, S.: Summertime coastal current reversal opposing offshore forcing and local wind near the middle east coast of Korea: Observation and dynamics, Geophys. Res. Lett., 43, 7097-7105, https://doi.org/10.1002/2016gl069322, 2016.

Park, J.-H and Nam, S.: Causes of interannual variation of summer mean alongshore current near the east coast of Korea derived from 16-year long observational data, J. Geophys. Res., in review, 2018.

Reifel, K. M., Corcoran, A. A., Cash, C., Shipe, R., and Jones, B. H.: Effects of a surfacing effluent plume on a coastal phytoplankton community, Cont. Shelf Res., 60, 38-50, https://doi.org/10.1016/j.csr.2013.04.012, 2013.

Ryu, J.-H., Han, H.-J., Cho, S., Park, Y.-J., and Ahn, Y.-H.: Overview of geostationary ocean color imager (GOCI) and GOCI data processing system (GDPS), Ocean Sci. J., 47, 223 233, https://doi.org/10.1007/s12601-012-0024-4, 2012.

Son, Y.-T., Chang, K.-I., Yoon, S.-T., Rho, T., Kwak, J. H., Kang, C. K., and Kim, K.-R.: A newly observed physical cause of the onset of the subsurface spring phytoplankton bloom in the southwestern East Sea/Sea of Japan, Biogeosciences, 11, 1319-1329, https://doi.org/10.5194/bg-11-1319-2014, 2014.

Warrick, J. A., DiGiacomo, P. M., Weisberg, S. B., Nezlin, N. P., Mengel, M., Jones, B. H., Ohlmann, J. C., Washburn, L., Terrill, E. J., and Farnsworth, K. L.: River plume patterns and dynamics within the Southern California Bight, Cont. Shelf Res., 27, 2427 2448, https://doi.org/10.1016/j.csr.2007.06.015, 2007.

Yin, K. D., Zhang, J. L., Qian, P. Y., Jian, W. J., Huang, L. M., Chen, J. F., and Wu, M. C. S.: Effect of wind events on phytoplankton blooms in the Pearl River estuary during summer, Cont. Shelf Res., 24, 1909-1923, https://doi.org/10.1016/j.csr.2004.06.015, 2004.

Yoo, S. and Kim, H. C.: Suppression and enhancement of the spring bloom in the southwestern East Sea/Japan Sea, Deep-Sea Res. Pt. II., 51, 1093-1111, https://doi.org/10.1016/j.dsr2.2003.10.008, 2004. 